RESEARCH REPORT

\title{
Neighbourhood environments and mortality in an elderly cohort: results from the cardiovascular health study
}

\author{
Ana V Diez Roux, Luisa N Borrell, Mary Haan, Sharon A Jackson, Richard Schultz
}

J Epidemiol Community Health 2004;58:917-923. doi: 10.1136/jech.2003.019596

See end of article for authors' affiliations

Correspondence to:

Dr A V Diez Roux, Department of

Epidemiology, Center for Social Epidemiology and Population Health, $1214 \mathrm{~S}$ University 2nd floor, Ann Arbor, MI 48104, USA; adiezrou@umich.edu

Accepted for publication 16 March 2004
Background: It has been postulated that neighbourhood conditions are related to the health of the elderly population but longitudinal studies are rare and confounding by individual level variables remains a possibility.

Methods: Data were obtained from the cardiovascular health study, a population based study of adults aged 65 years and older. Census block groups were used as proxies for neighbourhoods. A summary score was used to characterise the neighbourhood socioeconomic environment. Information on personal socioeconomic indicators, cardiovascular disease prevalence, and cardiovascular risk factors was obtained from the baseline examination. Proportional hazards regression and propensity score matching were used to control for individual level variables.

Results: Over the eight year follow up there were 1346 deaths among the 5074 participants, of which $43 \%$ were attributable to cardiovascular disease. Among white participants, living in the most disadvantaged neighbourhood group was associated with higher rates of cardiovascular death, after adjustment for income, education, and occupation (hazard ratio (HR) 1.5, 95\% confidence intervals (CI) 1.2 to 1.9). No neighbourhood differences were observed for non-cardiovascular deaths. Estimates for black participants were $1.3(95 \% \mathrm{Cl} 0.7$ to 2.3 ) for cardiovascular deaths and $1.4(95 \% \mathrm{Cl} 0.8$ to 2.4$)$ for non-cardiovascular deaths, but sample size was small. In white participants, associations of neighbourhood characteristics with cardiovascular mortality persisted after adjustment for prevalent baseline disease and cardiovascular risk factors. The use of propensity score matching led to similar results (HR for the lowest compared with the highest neighbourhood score group: $1.695 \% \mathrm{Cl} 1.1$ to 2.5 , controlling for personal socioeconomic indicators).

Conclusion: Neighbourhood disadvantage is related to rates of cardiovascular death in elderly white adults.
$\mathrm{D}$ espite longstanding interest among gerontologists in how neighbourhood environments may affect the health of the elderly population, ${ }^{1-6}$ most research on predictors of health and mortality in elderly cohorts has focused on personal factors related to disease status and health behaviours. ${ }^{7-9}$ Nevertheless, there are several reasons why the elderly may be especially vulnerable to the health enhancing or health damaging aspects of their immediate residential environments. ${ }^{4}{ }^{10}$ The activity space of individuals constricts with age ${ }^{11}$ and older persons may be more likely than working adults to spend time in their neighbourhoods. They may also be more likely to rely on their immediate environments for resources such as food shopping, recreational facilities, and health care. Older adults may be more vulnerable than younger adults to potentially adverse consequences of the physical features of their local environments (such as air pollution, pavement conditions, or heavy traffic). In addition, among the elderly, social interactions may also occur more frequently in the context of neighbourhoods, and features of neighbourhoods may influence the quantity and quality of social support experienced by residents. ${ }^{12} 13$

Cross sectional studies have found that living in disadvantaged neighbourhoods is associated with increased prevalence of poor self reported health and chronic conditions in the elderly, after controlling for personal socioeconomic indicators. ${ }^{14}$ Interpretation of these findings is difficult because of the possibility that the associations observed may result from reverse causation (for example, the movement of unhealthy persons into disadvantaged neighbourhoods). Although one study has found that features of residential environments are related to functional decline over time ${ }^{15}$ the extent to which neighbourhood characteristics are related to health in longitudinal studies has not been established.

Using data from the cardiovascular health study (CHS) we build on prior work in three ways. Firstly, we examine longitudinal associations between neighbourhood characteristics and mortality in a large, population based prospective study of persons 65 years of age and older with detailed information on individual level risk factors. Secondly, we examine if associations differ for cardiovascular disease and other causes. Prior work has outlined possible mechanisms through which neighbourhood environments could be specifically related to cardiovascular health. ${ }^{16}$ Reporting associations of neighbourhood characteristics with cardiovascular death but not with deaths attributable to other causes would provide additional evidence that neighbourhood factors are especially relevant to cardiovascular disease. Thirdly, we use the propensity score approach (in addition to standard multivariable adjustment) to control for individual level confounders. Multivariable adjustment may be limited in its ability to control for confounders in studies of neighbourhood effects and propensity score matching has been proposed as an alternative that may be especially useful when multiple confounders are involved..$^{17}$ This approach has not been used in studies of neighbourhood health effects.

\section{METHODS}

The CHS is a population based longitudinal study of coronary heart disease and stroke in adults 65 years of age and older. $^{1819}$ A total of 5201 men and women (242 black 
Table 1 Age adjusted mean neighbourhood characteristics and personal socioeconomic indicators at baseline in white participants who died and did not die, the cardiovascular health study, 1989-1993

\begin{tabular}{|c|c|c|c|c|c|c|c|c|c|c|}
\hline & \multicolumn{5}{|c|}{ White men } & \multicolumn{5}{|c|}{ White women } \\
\hline & $\begin{array}{l}\text { Died of } \\
\text { CVD } \\
(n=276)\end{array}$ & $\begin{array}{l}\text { Died of } \\
\text { other } \\
\text { causes } \\
(n=367)\end{array}$ & $\begin{array}{l}\text { Did not die } \\
(\mathrm{n}=1169)\end{array}$ & $\begin{array}{l}\mathrm{p} \text { Value } \\
\text { death } v \\
\text { no death }\end{array}$ & $\begin{array}{l}\mathrm{p} \text { Value } \\
\text { CVD death } \\
v \text { non-CVD } \\
\text { death }\end{array}$ & $\begin{array}{l}\text { Died of } \\
\text { CVD } \\
(n=218)\end{array}$ & $\begin{array}{l}\text { Died of } \\
\text { other } \\
\text { causes } \\
(\mathrm{n}=321)\end{array}$ & $\begin{array}{l}\text { Did not die } \\
(n=1866)\end{array}$ & $\begin{array}{l}\text { p Value } \\
\text { death } v \\
\text { no death }\end{array}$ & $\begin{array}{l}\text { p Value } \\
\text { CVD death } \\
v \text { non-CVD } \\
\text { death }\end{array}$ \\
\hline \multicolumn{11}{|l|}{ Mean neighbourhood characteristics } \\
\hline Neighbourhood score* & 2.7 & 2.9 & 3.8 & 0.0001 & 0.49 & 1.6 & 3.1 & 3.3 & 0.0004 & 0.0001 \\
\hline Median household income (\$) & 33500 & 33500 & 35400 & 0.01 & 0.90 & 30900 & 32800 & 33800 & 0.01 & 0.11 \\
\hline Median value of housing units (\$) & 100100 & 105700 & 115400 & 0.0001 & 0.24 & 95000 & 110000 & 111000 & 0.03 & 0.003 \\
\hline $\begin{array}{l}\text { Households with interest, dividends } \\
\text { or rent income (\%) }\end{array}$ & 48 & 48 & 52 & 0.0003 & 0.98 & 45 & 49 & 50 & 0.002 & 0.004 \\
\hline $\begin{array}{l}\text { Adult residents who completed high } \\
\text { school (\%) }\end{array}$ & 80 & 81 & 83 & 0.0001 & 0.67 & 78 & 82 & 82 & 0.006 & 0.0002 \\
\hline $\begin{array}{l}\text { Adult resident who completed } \\
\text { college (\%) }\end{array}$ & 27 & 29 & 32 & 0.0007 & 0.27 & 23 & 30 & 31 & 0.0009 & 0.0001 \\
\hline $\begin{array}{l}\text { Employed residents with executive, } \\
\text { managerial, or professional } \\
\text { occupation (\%) } \\
\text { Individual characteristics }\end{array}$ & 33 & 34 & 36 & 0.001 & 0.52 & 29 & 34 & 35 & 0.0008 & 0.0003 \\
\hline Annual income $\geqslant \$ 25,000$ (\%) & 43 & 45 & 53 & 0.0008 & 0.68 & 25 & 34 & 39 & 0.002 & 0.05 \\
\hline Complete college (\%) & 23 & 24 & 30 & 0.007 & 0.63 & 6 & 18 & 18 & 0.004 & 0.0001 \\
\hline $\begin{array}{l}\text { Executive/managerial/professional/ } \\
\text { administrative lifetime occupation (\%) }\end{array}$ & 46 & 47 & 55 & 0.001 & 0.9 & 20 & 26 & 25 & 0.5 & 0.1 \\
\hline
\end{tabular}

CVD, cardiovascular disease. *The neighbourhood score was constructed by summing Z scores for six neighbourhood level variables: median household income; median value of housing units; percentage of households receiving interest, dividend or net rental income; percentage adults with complete high school; percentage adults with complete college, and percentage of persons in managerial or professional specialty occupations.

participants and 4959 white participants) were recruited from four areas: Forsyth Co, NC; Washington Co, MD; Sacramento Co, CA; and Pittsburgh, PA. Participants were sampled from Medicare eligibility lists in each area. Eligible participants were 65 years or older at the time of the examination (June 1989-May 1990), not institutionalised, and did not require a proxy respondent at baseline. Overall, $57 \%$ of those eligible were enrolled in the study. In 1992-93, three of the four centres (Forsyth Co, Sacramento, and Pittsburgh) recruited an additional 687 black participants into the CHS cohort using the same sampling frame and data collection procedures used for the original cohort. The baseline interview and examination took place in 19891990 for the initial cohort and in 1992-93 for the supplemental cohort. Both cohorts have been followed up since then with semi-annual contacts. The two cohorts are combined for these analyses.

Participants were linked to their neighbourhood of residence using their baseline home address. US census defined block groups were used as proxies for neighbourhoods. Block groups are subdivisions of census tracts. On average, each block group includes about 1000 people. A summary neighbourhood score derived from 1990 US census data was used as an indicator of the neighbourhood

Table 2 Age adjusted mean neighbourhood characteristics and personal socioeconomic indicators at baseline in black participants who died and did not die, the cardiovascular health study, 1989-1993

\begin{tabular}{|c|c|c|c|c|c|c|c|c|c|c|}
\hline & \multicolumn{5}{|c|}{ Black men } & \multicolumn{5}{|c|}{ Black women } \\
\hline & $\begin{array}{l}\text { Died of } \\
\text { CVD } \\
(n=40)\end{array}$ & $\begin{array}{l}\text { Died of } \\
\text { other } \\
\text { causes } \\
(n=46)\end{array}$ & $\begin{array}{l}\text { Did not die } \\
(\mathrm{n}=\mathbf{2 3 5})\end{array}$ & $\begin{array}{l}p \text { Value } \\
\text { death } \\
v \text { no } \\
\text { death }\end{array}$ & $\begin{array}{l}\text { p Value CVD } \\
\text { death } v \text { non- } \\
\text { CVD death }\end{array}$ & $\begin{array}{l}\text { Died of } \\
\text { CVD } \\
(n=41)\end{array}$ & $\begin{array}{l}\text { Died of } \\
\text { other } \\
\text { causes } \\
(n=37)\end{array}$ & $\begin{array}{l}\text { Did not die } \\
(n=458)\end{array}$ & $\begin{array}{l}p \text { Value } \\
\text { death } v \\
\text { no death }\end{array}$ & $\begin{array}{l}\text { p Value CVD } \\
\text { death } v \text { non- } \\
\text { CVD death }\end{array}$ \\
\hline \multicolumn{11}{|l|}{ Neighbourhood characteristics } \\
\hline Neighbourhood score* & -3.5 & -2.7 & -1.8 & 0.02 & 0.21 & -2.9 & -4.1 & -2.7 & 0.16 & 0.13 \\
\hline Median household income (\$) & 19900 & 21400 & 23300 & 0.07 & 0.36 & 19200 & 19200 & 21100 & 0.15 & 0.96 \\
\hline Median value of housing units (\$) & 48400 & 59200 & 67900 & 0.02 & 0.09 & 54900 & 49900 & 61100 & 0.07 & 0.36 \\
\hline $\begin{array}{l}\text { Households with interest, dividends } \\
\text { or rental income (\%) }\end{array}$ & 20 & 22 & 26 & 0.03 & 0.65 & 23 & 17 & 22 & 0.36 & 0.06 \\
\hline $\begin{array}{l}\text { Adult residents who completed } \\
\text { high school }(\%)\end{array}$ & 65 & 68 & 71 & 0.04 & 0.40 & 66 & 62 & 67 & 0.06 & 0.20 \\
\hline $\begin{array}{l}\text { Adult resident who completed } \\
\text { college }(\%)\end{array}$ & 13 & 14 & 17 & 0.08 & 0.61 & 16 & 12 & 15 & 0.63 & 0.08 \\
\hline $\begin{array}{l}\text { Employed residents with executive, } \\
\text { managerial, or professional } \\
\text { occupation }(\%) \\
\text { Individual characteristics }\end{array}$ & 17 & 19 & 21 & 0.05 & 0.48 & 19 & 16 & 20 & 0.29 & 0.18 \\
\hline Annual income $\geqslant \$ 25000$ & 12 & 36 & 30 & 0.35 & 0.02 & 11 & 6 & 13 & 0.33 & 0.53 \\
\hline Complete college (\%) & 15 & 20 & 19 & 0.81 & 0.57 & 8 & 12 & 15 & 0.29 & 0.61 \\
\hline $\begin{array}{l}\text { Executive/managerial/professional/ } \\
\text { administrative lifetime occupation (\%) }\end{array}$ & 22 & 31 & 31 & 0.4 & 0.4 & 19 & 21 & 29 & 0.1 & 0.8 \\
\hline
\end{tabular}


Table 3 Age adjusted all cause mortality by race specific categories of neighbourhood summary score, the cardiovascular health study, 1989-1998

\begin{tabular}{|c|c|c|c|c|}
\hline \multirow[b]{2}{*}{ Neighbourhood tertile } & \multicolumn{2}{|l|}{ Men } & \multicolumn{2}{|l|}{ Women } \\
\hline & $\begin{array}{l}\text { Number } \\
\text { of events }\end{array}$ & $\begin{array}{l}\text { Rate per } 1000 \text { person } \\
\text { years }(95 \% \mathrm{Cl})\end{array}$ & $\begin{array}{l}\text { Number of } \\
\text { events }\end{array}$ & $\begin{array}{l}\text { Rate per } 1000 \text { person } \\
\text { years }(95 \% \mathrm{Cl})\end{array}$ \\
\hline \multicolumn{5}{|l|}{ White participants } \\
\hline 1 (Low) & 233 & 54 (47 to 61$)$ & 211 & 32 (29 to 35 ) \\
\hline 2 & 206 & 44 (38 to 50$)$ & 175 & 25 (22 to 28 ) \\
\hline 3 (High) & 204 & 38 (33 to 43 ) & 153 & 23 (21 to 26 ) \\
\hline \multicolumn{5}{|l|}{ African Americans } \\
\hline 1 (Low) & 28 & 52 (38 to 71$)$ & 32 & 28 (18 to 43 ) \\
\hline 2 & 30 & 60 (44 to 82 ) & 29 & 24 (15 to 39$)$ \\
\hline 2 (High) & 28 & 39 (28 to 54$)$ & 17 & $17(10$ to 30$)$ \\
\hline
\end{tabular}

socioeconomic environment. This score was constructed by summing Z scores for six variables representing the dimensions of wealth/income (median household income, median value of housing units, and percentage of households receiving interest, dividend or net rental income), education (percentage adults with complete high school, percentage adults with complete college), and occupation (percentage of persons in managerial or professional specialty occupations).$^{20}$ The rationale for the combination of these indicators has been previously described. ${ }^{20}$ Neighbourhood scores for block groups in the sample at baseline ranged from -10.7 to 16.7, with increasing score reflecting increasing neighbourhood socioeconomic advantage. Updated information on neighbourhood characteristics was also available for 1998 (year 8-9 of the initial cohort and year 5-6 of the supplemental cohort). Neighbourhoods were categorised into three groups of roughly equal size. Mean baseline neighbourhood scores for the three groups were $-1.8,2.9$, and 8.5 in white participants, and $-6.5,-3.6$, and 2.1 in black participants.

Information on personal income and education was collected as part of the baseline interview. Total combined family annual income was categorised as under $\$ 8000$; \$8000-\$15 999; \$16000 -\$34999; \$35 000-\$49 999; and $\$ 50000$ or more. Participants with no information on income $(6.5 \%)$ were coded as a separate category. Educational attainment was categorised as less than high school; high school or general equivalency diploma (including vocational school); one to three years of college; completed fours years of college; and some graduate or professional school. Occupation was defined as usual lifetime occupation and was selected from a response card as one of the following: I: professional/technical/managerial/ administrative; II: sales/ clerical service; III craftsman/machine operator/labourer; IV: farming/forestry; V: housewife; and VI: other/missing. Categories III and IV were combined in the analyses.

For analyses focusing on cardiovascular disease mortality, prevalence of cardiovascular disease (coronary heart disease, stroke, and congestive heart failure) at baseline was determined based on results of the baseline interview and examination. Self reports of disease were validated according to standardised criteria by ascertaining medications used and by relevant standardised examinations (such as electrocardiograms) performed on all study participants and/or medical record review. Information on the main cardiovascular risk factors (smoking, hypertension, diabetes, body mass index, total cholesterol, and HDL-cholesterol) was also obtained from the baseline examination. Smoking status was classified as current, former, or never smoker. Persons were defined as hypertensive if they had systolic blood pressure equal to or greater than $140 \mathrm{~mm} \mathrm{Hg}$, had diastolic blood pressure equal to or greater than $90 \mathrm{~mm} \mathrm{Hg}$, or were taking antihypertensive medications. Persons were defined as diabetic if they had fasting plasma glucose equal to or greater than $7 \mathrm{mmol} / \mathrm{l}$ ) or were taking medications for diabetes.

Participants were reinterviewed every six months. Confirmation of deaths was conducted through reviews of obituaries, medical records, death certificates, and the US Health Care Financing Administration (HCFA) health care utilisation database for stays in hospital. There was $100 \%$ complete follow up ascertainment of mortality status. Cardiovascular deaths (including atherosclerotic coronary

Table 4 Adjusted hazard ratios of mortality (all cause, cardiovascular disease, and other causes) by race specific categories of neighbourhood summary score, the cardiovascular health study, 1989-1998

\begin{tabular}{|c|c|c|c|c|c|c|}
\hline \multirow[b]{3}{*}{ Neighbourhood group } & \multicolumn{6}{|c|}{ Hazard ratios $(95 \% \mathrm{CI})$} \\
\hline & \multicolumn{2}{|l|}{ All cause } & \multicolumn{2}{|c|}{ Cardiovascular disease } & \multicolumn{2}{|l|}{ Other causes } \\
\hline & $\begin{array}{l}\text { Adjusted for } \\
\text { age and sex }\end{array}$ & $\begin{array}{l}\text { Adjusted for age, } \\
\text { sex, income, } \\
\text { education, and } \\
\text { occupation* }\end{array}$ & $\begin{array}{l}\text { Adjusted for } \\
\text { age and sex }\end{array}$ & $\begin{array}{l}\text { Adjusted for age, } \\
\text { sex, income, education, } \\
\text { and occupation }\end{array}$ & $\begin{array}{l}\text { Adjusted for } \\
\text { age and sex }\end{array}$ & $\begin{array}{l}\text { Adjusted for age, sex, } \\
\text { income, education, and } \\
\text { occupation }\end{array}$ \\
\hline \multicolumn{7}{|l|}{ White people } \\
\hline 1 (Low) & $1.4(1.2$ to 1.6$)$ & $1.2(1.0$ to 1.4$)$ & $1.9(1.5$ to 2.4$)$ & 1.5 (1.2 to 1.9$)$ & $1.2(1.0$ to 1.4$)$ & $1.0(0.8$ to 1.3$)$ \\
\hline 2 & 1.1 (1.0 to 1.3$)$ & $1.0(0.9$ to 1.2$)$ & $1.4(1.1$ to 1.8$)$ & $1.2(1.0$ to 1.6$)$ & $1.0(0.8$ to 1.2$)$ & $0.9(0.7$ to 1.1$)$ \\
\hline 3 (High) & 1.0 & 1.0 & 1.0 & 1.0 & 1.0 & 1.0 \\
\hline $\begin{array}{l}\mathrm{p} \text { Value for trend } \\
\text { African Americans }\end{array}$ & $<0.0001$ & 0.02 & $<0.0001$ & 0.001 & 0.11 & 0.8 \\
\hline 1 (Low) & $1.4(1.0$ to 2.1$)$ & $1.3(0.9$ to 1.9$)$ & 1.5 (0.9 to 2.7$)$ & $1.2(0.7$ to 2.2$)$ & $1.3(0.8$ to 2.3$)$ & $1.4(0.8$ to 2.4$)$ \\
\hline 2 & 1.5 (1.0 to 2.2$)$ & 1.5 (1.0 to 2.2$)$ & $1.8(1.1$ to 3.0$)$ & 1.7 (1.0 to 2.8$)$ & $1.3(0.7$ to 2.1$)$ & $1.4(0.8$ to 2.4$)$ \\
\hline 3 (High) & 1.0 & 1.0 & 1.0 & 1.0 & 1.0 & 1.0 \\
\hline $\mathrm{p}$ Value for trend & 0.08 & 0.2 & 0.2 & 0.5 & 0.3 & 0.3 \\
\hline
\end{tabular}


Table 5 Baseline individual level covariates for participants in lowest and highest neighbourhood score groups for the full sample and for propensity score matched pairs, the cardiovascular health study, 1989-1993

\begin{tabular}{|c|c|c|c|c|}
\hline & \multicolumn{2}{|c|}{ Full sample $(n=2890)$} & \multicolumn{2}{|c|}{$\begin{array}{l}\text { Propensity score* matched pairs } \\
\text { ( } n=1010,505 \text { matched pairs) }\end{array}$} \\
\hline & $\begin{array}{l}\text { Group } 1 \text { (Lowest) } \\
n=1390\end{array}$ & $\begin{array}{l}\text { Group } 3 \text { (Highest) } \\
n=1434\end{array}$ & $\begin{array}{l}\text { Group } 1 \text { (Lowest) } \\
\mathrm{n}=505\end{array}$ & $\begin{array}{l}\text { Group } 3 \text { (Highest) } \\
n=505\end{array}$ \\
\hline$\%$ Female & 59 & 56 & 58.2 & 57.2 \\
\hline \multicolumn{4}{|l|}{ Income (\% distribution) } & 72.7 \\
\hline$<\$ 5000$ & 5.9 & 0.8 & 1.0 & 1.8 \\
\hline$\$ 5000-\$ 7999$ & 11.0 & 2.4 & 5.9 & 4.6 \\
\hline$\$ 8000-\$ 11999$ & 14.8 & 5.3 & 9.9 & 9.5 \\
\hline$\$ 12000-\$ 15999$ & 19.6 & 8.9 & 14.1 & 16.0 \\
\hline$\$ 16000-\$ 24999$ & 20.7 & 14.9 & 25.7 & 24.6 \\
\hline$\$ 25000-\$ 34999$ & 14.0 & 15.3 & 16.4 & 18.2 \\
\hline$\$ 35,000-\$ 49999$ & 4.9 & 14.6 & 9.7 & 10.3 \\
\hline$\geqslant \$ 50000$ & 4.5 & 28.8 & 10.5 & 8.3 \\
\hline $\begin{array}{l}\text { Unknown } \\
\text { Education (\% distribution) }\end{array}$ & 4.8 & 9.0 & 6.9 & 6.7 \\
\hline Less than complete high school & 42.0 & 10.6 & 20.0 & 22.4 \\
\hline Complete high school & 39.2 & 33.0 & 48.3 & 46.9 \\
\hline $1-3$ years college & 8.9 & 18.1 & 16.4 & 13.5 \\
\hline Complete 4 year college & 5.4 & 20.0 & 8.1 & 11.1 \\
\hline \multicolumn{4}{|l|}{ Occupation (\%distribution) } & 6.1 \\
\hline $\begin{array}{l}\text { Professional/technical/ } \\
\text { managers }\end{array}$ & 25.3 & 47.2 & 37.4 & 36.1 \\
\hline Sales/clerical/service & 13.9 & 18.3 & 17.6 & 21.4 \\
\hline $\begin{array}{l}\text { Craftsmen/machine operators/ } \\
\text { farming/forestry }\end{array}$ & 25.0 & 6.4 & 12.9 & 14.9 \\
\hline Homemaker & 24.5 & 21.7 & 22.0 & 19.3 \\
\hline Other/missing & 11.3 & 6.4 & 10.1 & 8.3 \\
\hline \multicolumn{5}{|c|}{$\begin{array}{l}\text { *Propensity scores constructed by modelling the odds of living in the lowest neighbourhood tertile (compared witl } \\
\text { the highest tertile) as a function of age, sex, income (nine categories shown), education (five categories shown), } \\
\text { occupation (five categories shown), the interactions of sex with all other covariates, and all two way interaction } \\
\text { between income, education, and occupation. For the full sample, distributions of income, education, and } \\
\text { occupation differed significantly across groups ( } p 0.0001 \text { for all three). For the propensity score matched sets, } \\
\text { distributions of income, education, and occupation did not differ significantly across groups ( } p=0.8 \text { for income } \\
p=0.3 \text { for education; and } p=0.5 \text { for occupation). }\end{array}$} \\
\hline
\end{tabular}

heart disease, cerebrovascular disease, other atherosclerotic disease, and other cardiovascular deaths) were adjudicated by committee based on a CHS protocol. ${ }^{21}$ Deaths to 31 December 1998 were included in these analyses. Median and maximum follow up times were 8.1 years and 8.8 years for the initial cohort and 5.0 and 5.5 years for the supplemental cohort.

Of the 5888 participants at baseline, 5174 matched to block groups with available census data. Of these, 47 were excluded because they matched to block groups with less than 100 persons, less than 30 housing units per block, or with 33\% or more persons in group quarters. Seventeen participants were excluded because information on education was unavailable and an additional 32 participants were excluded because their race was neither black nor white. Four participants who died were excluded because no information on cause of death was available leaving a total of 5074 participants in 908 block groups available for analysis (median of three participants per block group).

Because of important race differences in the distribution of neighbourhood characteristics and personal socioeconomic indicators, analyses were stratified by race and different categories (based on the race specific distributions) were used in each race. Patterns were roughly similar in both sexes and tests for interaction were not statistically significant in final models. Results for final models are therefore presented for both sexes combined and adjusted for sex. Baseline values of neighbourhood characteristics and personal socioeconomic indicators were compared for participants who died and who did not die over follow up (as well as for participants who died of cardiovascular disease and those who died of other causes) using linear and logistic regression. Mortality rates were calculated by dividing the number of deaths by the person years of follow up within race specific groups of neighbourhood score. Proportional hazards regression was used to obtain hazard ratios of death by groups of neighbourhood score after adjustment for age and sex and after additional adjustment for personal income, education, and occupation. Models for cardiovascular disease mortality were rerun after adjustment for prevalence of cardiovascular disease and baseline levels of cardiovascular risk factors. There was no evidence that the hazards were not proportional over the follow up period studied. Tests for trend were performed by introducing neighbourhood groups as an ordinal variable in regressions. In analyses focusing on specific causes of death, deaths attributable to other causes were treated as censored at the time of death. Differences in associations of neighbourhood characteristics with cardiovascular mortality and non-cardiovascular mortality were tested using the approach proposed by Lagakos. ${ }^{22}$

\section{Key points}

- Neighbourhood disadvantage is associated with increased cardiovascular disease mortality in US white people over 65 years of age.

- These associations seem to be independent of personal socioeconomic indicators. 
As an alternative to standard multivariable adjustment, we estimated propensity scores for living in the lowest category of neighbourhood disadvantage compared with the highest. ${ }^{23}{ }^{24}$ Propensity scores were constructed by modelling the odds of living in the lowest neighbourhood tertile (compared with the highest tertile) as a function of age, sex, income, education, occupation, the interactions of sex with all other covariates, and all two way interactions between income, education, and occupation. Models for propensity scores were also run including prevalence of cardiovascular disease and baseline cardiovascular risk factors. Regression models to estimate hazard ratios of death in lowest compared with highest tertile of neighbourhood score were then rerun on propensity score matched pairs, ${ }^{25}$ with each person in the lowest neighbourhood tertile matched to another in the highest tertile with a similar propensity score (equal in the first three digits). Observations that could not be matched were excluded from propensity score analyses.

In addition to estimating hazard ratios associated with neighbourhood characteristics we estimated the rate advancement period $^{26}$ for persons living in the most disadvantaged tertile compared with the most advantaged tertile. The rate advancement period is estimated by comparing the coefficient for the exposure of interest with the coefficient for the baseline age effect in the same model. It is appropriate for events that increase monotonically with age (as do most chronic diseases), and for situations in which the timing of events (that is, when the event occurs as compared with simply whether it occurs) is of special interest (as in the case of death). The rate advancement period is a measure of the time period by which the rate of disease is advanced among exposed subjects. For example, a rate advancement period of five years for exposed subjects would imply that the effect of exposure is equivalent to an increase of five years in baseline age). In proportional hazards models SUDAAN $^{27}$ was used to account for potential within neighbourhood correlations in outcomes. Results were virtually identical to those obtained using standard regression approaches, suggesting that within neighbourhood correlations in the outcomes was negligible. Because the structure of the data (with comparatively few participants per block group) limited our ability to partition variance in the outcome into within and between neighbourhood components, multilevel models were not used. This research was approved by the appropriate ethics committees and conformed to the principles embodied in the Declaration of Helsinki.

\section{RESULTS}

There were 1346 deaths among the 5074 participants, of which $575(43 \%)$ were attributable to cardiovascular disease. White participants who died over the follow up were generally more likely to live in disadvantaged neighbourhoods at baseline than those who did not (table 1). In addition, white participants who died of cardiovascular causes were even more likely to live in disadvantaged neighbourhoods than those who died of non-cardiovascular causes. In general, similar patterns to those observed for white participants were present in black participants (table 2), although the number of black participants was small, and differences were sometimes not statistically significant.

\section{Policy implications}

Policies to prevent cardiovascular disease may need to take account of features of residential environments.
All cause mortality rates generally decreased with increasing neighbourhood score (table 3 ). There was no evidence of multiplicative interaction between gender and neighbourhood characteristics for all cause, cardiovascular, or noncardiovascular disease mortality in white or black participants. In white participants, associations of neighbourhood score with mortality were reduced after adjustment for income, education, and lifetime occupation (table 4), but differences between the worse off and best off neighbourhood categories remained for cardiovascular deaths. Living in the most disadvantaged neighbourhood tertile was associated with a 50\% higher hazard of cardiovascular death, after adjustment for income, education, and lifetime occupation. Neighbourhood characteristics were not associated with noncardiovascular deaths in white participants ( $p$ value for difference in associations of neighbourhood characteristics with CVD deaths and non-CVD deaths <0.001). In black participants, the highest risk of all cause mortality and cardiovascular disease mortality was observed in the middle neighbourhood category but consistent trends across categories were not observed and there was no evidence that associations of neighbourhood characteristics with mortality differed by cause of death. Results reported in table 4 were virtually identical after additional adjustment for study site. Interactions between site and neighbourhood tertile were not statistically significant in any of the models.

In white participants, neighbourhood characteristics were still associated with cardiovascular death after controlling for age, sex, income, education, and occupation when analyses were restricted to the 3268 persons without prevalent cardiovascular disease at baseline (HR 1.8 95\%CI 1.2 to 2.6 and $1.695 \%$ CI 1.2 to 2.3 for lowest neighbourhood score group and middle neighbourhood score group, respectively). In the full sample of white participants, associations were weakened but persisted after controlling for prevalent clinical disease and cardiovascular risk factors at baseline in proportional hazards regression models (hazard ratios (95\% CI): 1.3 ( 1.0 to 1.7 ) and 1.2 (0.9 to 1.5$)$ for the lowest and middle neighbourhood score groups, respectively; $\mathrm{p}$ for trend across groups: 0.03).

As expected there were important differences in personal socioeconomic indicators between the lowest and highest neighbourhood score groups (table 5). Propensity score matching reduced the number of participants available for analysis but resulted in adequate balance of relevant covariates across both groups (table 5). Associations between neighbourhood disadvantage and cardiovascular death remained, even when analyses were restricted to 505 matched propensity score pairs (HR for the lowest compared with the highest neighbourhood score group: 1.6 95\%CI 1.1 to 2.5 ), with scores based on age, sex, income education, and occupation as described in the Methods section. When baseline prevalence of cardiovascular disease and cardiovascular risk factors were included in the propensity score model, neighbourhood disadvantage continued to be associated with increased hazard of cardiovascular death (HR 1.4 95\%CI 0.9 to 2.1 based on 908 participants in 454 matched pairs), although possibly because of reduced sample size the confidence interval was wide and included 1 .

In white participants, the increased risk of cardiovascular death associated with living in the most disadvantaged third of neighbourhoods was equivalent to being four years older at baseline (rate advancement period 4.1 95\%CI 1.6 to 6.6). When low income persons (incomes $<\$ 16000$ ) residing in the most disadvantaged third of neighbourhoods were compared with high income persons (incomes of $\$ 35000$ or more) residing in the most advantaged third, the rate advancement period was 9.7 years (95\% CI 5.8 to 13.6) for cardiovascular deaths in white participants. 


\section{DISCUSSION}

Among white elderly adults, living in the most disadvantaged third of neighbourhoods was associated with a 50\% increased hazard rate of cardiovascular death over an eight year follow up, even after accounting for personal income, education, and lifetime occupation. No increased risk was observed for non-cardiovascular causes. Among black study participants, point estimates indicated a $20 \%$ and $40 \%$ increased hazard rate of cardiovascular deaths and non-cardiovascular deaths respectively, but the limited number of black participants resulted in wide confidence intervals. For cardiovascular deaths in white participants, the increased risk of death associated with living in the most disadvantaged third of neighbourhoods was equivalent to the increased risk conferred by being four years older at baseline.

To date, several studies have investigated the relation between area or neighbourhood of residence and mortality. ${ }^{28-35}$ None focused specifically on elderly cohorts, but among studies that stratified results by age associations seem to weaken or disappear in older participants. ${ }^{28}{ }^{32}{ }^{36}$ Anderson et $a l^{28}$ found no association between census tract income and all cause mortality in persons 65 years of age or over after controlling for personal income. Waitzman and Smith ${ }^{36}$ and Haan $e t a^{32}$ also found no association between poverty area residence and mortality in older adults. The absence of associations of area characteristics with mortality in the elderly may result from substantive differences in neighbourhood effects, from survivor effects, or from the fact that estimates using ratio measures usually decline when the baseline risk increases (as death rates do with age). In our analyses, neighbourhood characteristics were associated with cardiovascular disease mortality, but not with non-cardiovascular disease mortality, in white participants aged 65 years and over. No differences in associations by cause of death were observed in black particpants but sample size was small. Small numbers made it impossible to examine associations with specific causes within the non-cardiovascular deaths.

The stronger effect observed for cardiovascular deaths is consistent with work in middle aged cohorts reporting differences in coronary heart disease incidence across neighbourhoods. ${ }^{37}$ The presence of this differential suggests that investigation of the specific processes through which residential environments could affect cardiovascular health is warranted. This may entail studying the relation between specific physical and social features of spatial contexts relevant to the elderly and specific behaviours, psychosocial attributes, or biological processes. The fact that associations were present even among persons with no prevalent disease at baseline suggests that differences are not attributable exclusively to precipitation of death in persons with prior disease. Associations with cardiovascular death also persisted after controlling for traditional cardiovascular risk factors. However, because of limitations in multivariable adjustment techniques to separate "direct" and "indirect" effects ${ }^{38}$ we caution against concluding that associations of neighbourhoods with cardiovascular risk are not mediated (at least in part) by cardiovascular risk factors.

The weaker patterns observed in black participants are consistent with other work showing weaker associations of neighbourhood characteristics with cardiovascular risk in black persons than in white persons in other US samples. ${ }^{37}$ However, differences in the range of neighbourhoods compared in both race groups, as well as sample size differences, make it difficult to draw firm conclusions regarding interactions of neighbourhood characteristics with race from these data.

Although many individual level variables controlled for in studies of neighbourhood health effects (including this study) may be thought of as mediators rather than confounders of these effects, insufficient control for possible individual level confounders continues to be a key criticism of this work. Measures of personal income, education, or occupation (which may be related to the likelihood of living in a disadvantaged neighbourhood and are also related to mortality) are viewed as key confounders. Traditional multiple regression adjustment strategies are limited in controlling for these factors because there is often comparatively little overlap in the personal income, education, and occupation distributions for persons living in very different neighbourhoods. Thus model estimates may be based on extrapolations based on assumptions that cannot be directly examined in the data.

As a way to address this criticism, we used propensity score matching to confirm the results obtained from multiple regression. Propensity score matching restricts the analysis to persons with comparable propensity scores, and hence comparable levels of individual level risk factors, as shown in table 5. Thus the criticisms that estimates are based on extrapolations beyond the ranges supported by the data are no longer valid. In propensity score analyses, living in the most disadvantaged neighbourhood tertile continued to be strongly and significantly associated with cardiovascular death in white participants ( HR $1.695 \%$ CI 1.1 to 2.5). This estimate was in fact quite similar to that obtained from the multiple regression models. It is of course possible that measurement error in individual level socioeconomic measures (including the limitations of income as a marker for personal wealth in the elderly population), ${ }^{39}$ may have resulted in overestimates of the relation between neighbourhood characteristics and mortality, even when propensity scores were used. An additional limitation of propensity score matching is that the analysis is necessarily restricted to the matched sets that may not be representative of the full sample. This approach however, is preferable to approaches that include propensity scores in the regression model using the full data because it ensures that the observations used to estimate the association of interest are truly comparable on the confounders (as shown in table 5). Our results from the propensity score matched analysis strengthens the evidence that the associations observed are not attributable to inadequate adjustment for measured personal socioeconomic indicators in standard multiple regression models.

A limitation of investigating neighbourhood effects on mortality in an elderly cohort is that elderly persons who reside in poor neighbourhoods may be a healthy subsample simply because they are selected for having survived into old age despite living in disadvantaged environments. This could result in underestimates of true neighbourhood effects. In our analyses, estimates of neighbourhood differences were based on place of residence at the time of the baseline examination of the cohort. The cohort was quite stable over follow up. Information on block group of residence for the latest updated address available in 1998 was obtained for 4665 study participants (92\% of the sample included in these analyses). Of these, $73 \%$ lived in the same block groups at both times. Among those who had moved, 49\% remained in the same tertile of neighbourhood score, $25 \%$ had moved up, and $26 \%$ had moved down. Although short term effects of place of residence on mortality in the elderly are plausible, it may be that residential environments over the life course, rather than place of residence in old age, is particularly relevant to longevity. Unfortunately, information on long term residence before enrolment in the study was unavailable, and the extent to which features of place of residence in old age are correlated with features of places earlier in life (or with socioeconomic position earlier in life) in this sample cannot be established. Moreover, the lag times over which neighbourhood effects may operate may differ for different 
types of health outcomes. The investigation of these more complex questions requires studies that follow up places and people over time.

The CHS sample was drawn from only four study sites. Although the range of block group characteristics represented was quite large, these block groups are obviously not a random sample of the US block groups and are therefore not representative of the whole country. It is possible that national studies, or studies focusing on large urban areas (which our sample did not include), may find different results. Unfortunately the structure of the data, with few people per neighbourhood, did not permit modelling of between and within neighbourhood variability in the outcome using multilevel models. Nevertheless, the presence of multiple neighbourhoods does permit adequate estimation of the fixed effects of neighbourhood level variables (our main research question).$^{40}$

An additional limitation of these analyses is the use of census defined block groups as proxies for the spatial contexts relevant to health of the elderly population. Block groups are obviously very crude proxies for the different types of areas potentially relevant to the health of elderly people. Mis-specification of the relevant context may have limited our ability to detect neighbourhood contextual effects. The summary neighbourhood score we used may be an inadequate proxy for the features of neighbourhoods that may be relevant to the health of the elderly population. The observational nature of the study also makes it impossible to conclude from these data alone that the associations we observe reflect causal processes. Our results show that in the white population (among whom sample size was largest) neighbourhood disadvantage was associated with increased risk of cardiovascular death. Similar associations were observed when analyses were restricted to propensity score matched sets, suggesting that these associations do not result from inadequate adjustment for measured socioeconomic indicators in standard multivariate models. Further work that elucidates the processes possibly underlying this association may help develop more effective policies to prolong life in elderly adults.

\section{Authors' affiliations}

A V Diez Roux, M Haan, Department of Epidemiology, University of Michigan School of Public Health, Ann Arbor, USA

L N Borrell, Department of Epidemiology, Mailman School of Public Health, New York, USA

S A Jackson, Department of Public Health Sciences, Wake Forest University School of Medicine, Winston Salem, USA

R Schultz, University Center for Social and Urban Research, School of Medicine, University of Pittsburgh, Pittsburgh, USA

Funding: this work was supported by R29 HL59386 (Dr Diez-Roux) from the National Heart, Lung and Blood Institute. CHS was supported by contracts N01-HC-85079---N01-HC-85086 from the National Heart, Lung, and Blood Institute, and Georgetown Echo RC - HL $35129 \mathrm{JHU}$ MRI RC- HL 15103.

Conflicts of interest: none declared.

\section{REFERENCES}

1 Bohland J, Davis L. Sources of residential satisfaction among the elderly. In: Golant S, ed. Location and environment of elderly populations. New York: Wiley, 1979.

2 Carp F. Environment and aging. In: Altman I, ed. Handbook of environmental psychology. New York: Wiley, 1979.

3 Carp F. Assessing the environment. Annu Rev Gerontol Geriatr 1994; 14:302-23.

4 Lawton M. The impact of the environment on aging and behavior. In: Schaie K, ed. Handbook on the psychology of aging. New York: Van Nostrand Reinhold, 1977
5 Lawton M. Environment and aging. Monterey, CA: Brooks Cole, 1980

6 Lawton M, Nahemow L, Yeh T. Neighborhood environment and the well being of older tenants in planned housing. Int J Aging Human Dev 1980;11:211-27.

7 Campbell A, Diep C, Reinken J, et al. Factors predicting mortality in a total population sample of the elderly. J Epidemiol Community Health 1985;39:337-42.

8 Fried L, Kronmal R, Newman A. Risk factors for 5-year mortality in older adults. The cardiovascular health study. JAMA 1998;279:585-92.

9 Stamler J, Dyer A, Shekelle R, et al. Relationship of baseline major risk factors to coronary and all-cause mortality, and to longevity: findings from long-term follow-up of Chicago cohorts. Cardiology 1993;82:191-222.

10 LaGory M, Fitzpatrick K. The effects of environmental context on elderly depression. J Aging Health 1992;4:459-79.

11 Stea D. Home range and use of space. In: Carson D, ed. Spatial behavior of older people. Ann Arbor, MI: Institute of Gerontology, 1970:138-47.

12 Krause N. Neighborhood deterioration and social isolation in later life. Int J Aging Human Dev 1993;11:342-52.

13 Skjaeveland O, Garling T. Effects of interactional space on neighboring. J Environ Psychol 1997;17:181-98.

14 Robert S. Community-level socioeconomic status effects on adult health $J$ Health Soc Behav 1998;39:18-37.

15 Balfour J, Kaplan G. Neighborhood environment and loss of physical function in older adults: evidence from the Alameda County Study. Am J Epidemiol 2002;155:507-15

16 Diez-Roux AV, Nieto FJ, Muntaner C, et al. Neighborhood environments and coronary heart disease: a multilevel analysis. Am J Epidemiol 1997; 146:48-63.

17 D'Agostino R. Propensity score methods for bias reduction in the comparison of a treatment to non-randomized control group. Stat Med 1998;17:2265-81.

18 Fried LP, Borhani NO, Enright $P$, et al. The cardiovascular health study: design and rationale. Ann Epidemiol 1991;1:263-76.

19 Tell G, Fried L, Hermanson B, et al. Recuitment of adults sixty-five years and older as participants in the cardiovascular health study. Ann Epidemiol 1993:3:358-66.

20 Diez Roux AV, Kiefe Cl, Jacobs DR Jr, et al. Area characteristics and individual-level socioeconomic position indicators in three population-based epidemiologic studies. Ann Epidemiol 2001;11:395-405.

21 Ives DG, Fitzpatrick AL, Bild DE, et al. Surveillance and ascertainment of cardiovascular events. The Cardiovascular Health Study. Ann Epidemiol 1995;5:278-85.

22 Lagakos S. A covariate model for partially censored data subject to competing causes of failure. Applied Statistics 1978;27:235-41.

23 Joffe M, Rosenbaum P. Propensity scores. Am J Epidemiol 1999;150:327-33.

24 Rubin D. Estimating causal effects from large data sets using propensity score. Ann Intern Med 1997; 127:757-63.

25 Parsons L. Using SAS software to perform a case-control match on propensity score in an observational study. Proceedings of the twenty-fifth annual SAS users group international conference, Cary, NC, SAS Institute, 2000:1 166-71

26 Brenner H, Gefeller O, Greenland S. Risk and rate advancement periods as measures of exposure impact on the occurrence of chronic diseases. Epidemiology 1993;4:229-36.

27 Shah B, Barnwell B, Bieler G. SUDAAN user's manual, release 7.5. Research Triangle Park, NC: Research Triangle Institute, 1997

28 Anderson R, Sorlie P, Backlund E, et al. Mortality effects of community socioeconomic status. Epidemiology 1996;8:42-7.

29 Bosma H, van de Mheen HD, Borsboom GJ, et al. Neighborhood socioeconomic status and all-cause mortality. Am J Epidemiol 2001;153:363-71

30 Davey Smith G, Hart C, Watt G, et al. Individual social class, area-based deprivation, cardiovascular disease risk factors, and mortality: the Renfrew and Paisley study. J Epidemiol Community Health 1998;52:399-405.

31 Ecob R, Jones K. Mortality variations in England and Wales between types of place: an analysis of the ONS longitudinal study. Soc Sci Med 1998;47:2055-66.

32 Haan M, Kaplan G, Camacho T. Poverty and health: prospective evidence from the Alameda County study. Am J Epidemiol 1987;125:989-98.

33 LeClere. Ethnicity and mortality in the United States: individual and community correlates. Social Forces 1997;76:169-98.

34 Sloggett A, Joshi H. Higher mortality in deprived areas: community or personal disadvantage? BMJ 1994;309:1470-4.

35 Yen I, Kaplan G. Neighborhood social environment and risk of death: multilevel evidence from the Alameda County study. Am J Epidemiol 1999;149:898-907

36 Waitzman N, Smith K. Phantom of the area: poverty-area residence and mortality in the United States. Am J Public Health 1998;88:973-6.

37 Diez Roux AV, Merkin SS, Arnett D, et al. Neighborhood of residence and incidence of coronary heart disease. N Engl J Med 2001;345:99-106.

38 Robins JM, Greenland S. Identifiability and exchangeability for direct and indirect effects. Epidemiology 1992;3:143-55.

39 Berkman $L$. The changing and heterogeneous nature of aging and longevity: a social biomedical perspective. Annu Rev Gerontol Geriatr 1988;8:37-68.

40 Snijders TAB, Bosker R. Multilevel analysis: an introduction to basic and advanced multilevel modeling. London: Sage, 1999. 